\title{
Medium-term clinical results after the Senning procedure with haemodynamic and angiographic evaluation of the venous pathways
}

\author{
W C Dihmis, J A Hutter, H S Joffe, J P Dhasmana, S C Jordan, J D Wisheart
}

\begin{abstract}
Objective-To assess the clinical condition of patients and the adequacy of their newly constructed venous pathways after the Senning operation for simple transposition of the great arteries.

Patients and design-All 34 patients who had the Senning operation between March 1983 and December 1986 were reviewed. Survivors had detailed cardiac catheterisation studies one to two years later and clinical evaluation two to six years after surgery.
\end{abstract}

Results-There were two operative deaths $(6 \%)$, one sudden late death (after two years), and 31 survivors (91\%). No clinical evidence of obstructed venous pathways was found and there was no need for reoperation for any reason. The average mean (SD) pressure gradient at the junction of the superior vena cava and systemic venous atrium was $2.0(1 \cdot 7)$ mm $\mathrm{Hg}$, although two patients had gradients of $7 \mathrm{~mm} \mathrm{Hg}$. The average gradient was 0.7 (1) $\mathrm{mm} \mathrm{Hg}$ in the inferior vena caval pathway, and $1.4(1 \cdot 1) \mathrm{mm} \mathrm{Hg}$ between the mean pulmonary arterial wedge and pulmonary venous atrial pressures. Only the two patients with gradients of $7 \mathrm{~mm} \mathrm{Hg}$ at the junction of the superior vena cava and the systemic venous atrium had considerable narrowing of the pathway and retrograde flow in the azygos vein to below the diaphragm. Conclusion-A small series of patients were comprehensively studied after the Senning operation for simple transposition of the great arteries. Scrupulous technique in the construction of the venous pathways has had excellent results with no need for reoperation for obstruction in either the systemic or pulmonary pathways. Clinical observation alone may fail to identify patients with venous pathway obstruction, therefore careful assessment is required, even in patients who are physically normal.

(Br Heart f 1993;69:436-441)

The Senning technique for physiological correction of transposition of the great arteries, ${ }^{1}$ as modified by Quaegebeur and Brom, ${ }^{2}$ avoids or minimises the use of foreign material. This development was prompted by the occurrence of obstruction to the venous pathways $^{34}$ and atrial arrhythmias ${ }^{5,6}$ after the
Mustard operation, which used either autologous pericardium or synthetic material, and which had otherwise good results. ${ }^{7-9}$ In response to concern regarding the long-term ability of the right ventricle to maintain the systemic circulation, an anatomical correction was devised ${ }^{10-12}$ that is now being used increasingly for simple transposition of the great arteries in the neonatal period. ${ }^{13}$ Because of the high incidence of venous pathway obstruction after the Mustard correction at this institution, ${ }^{4}$ we have used the Senning procedure since 1983 . We report our experience in simple transposition of the great arteries with particular attention to the angiographic and haemodynamic features of the venous pathways.

\section{Patients and methods}

PATIENTS

Records of the first 34 patients with simple transposition of the great arteries corrected by the Senning procedure between March 1983 and December 1986 at the Bristol Royal Infirmary were reviewed and survivors were electively recalled for detailed cardiac catheterisation studies at least one year after the Senning repair and for continuing clinical assessment. The diagnosis of transposition of the great arteries had been confirmed in each baby by cardiac catheterisation between the first and 16th day after birth (mean (SD) $6 \cdot 1$ $(8 \cdot 6)$ days). A balloon atrial septostomy ${ }^{14}$ was performed during the catheterisation procedure that resulted in a rise in oxygen saturation from $52 \%(9 \cdot 6 \%)$ to $75 \%(11.5 \%)$.

As well as simple transposition of the great arteries a small ventricular septal defect was present in three cases, a patent ductus arteriosus in one, coarctation of the aorta in two, and an aberrant brachiocephalic artery in one case. Patients with a large ventricular septal defect or severe subpulmonary stenosis ( $>40$ $\mathrm{mm} \mathrm{Hg}$ ) were excluded from the study. Mild subpulmonary stenosis was present in 17 patients with a mean gradient of $14.8(9.2)$ $\mathrm{mm} \mathrm{Hg}$ across the left ventricular outflow tract.

During the study period the average age at the time of the Senning operation was 18.5 $(7 \cdot 5)$ months (weight 9.1 $(2 \cdot 3) \mathrm{kg}$ ). Subsequently the operation has been done at a much earlier age. Of the two patients with coarctation, one had hypoplasia of the aortic arch, which was bypassed at the age of two months with a six mm Dacron graft placed between the ascending and descending aorta.

Department of
Cardiac Surgery,
Bristol Royal
Infirmary, and Bristol
Royal Hospital for
Sick Children
W C Dihmis
J A Hutter
J P Dhasmana
J D Wisheart
Department of
Pediatric Cardiology,
Bristol Royal
Infirmary, and Bristol
Royal Hospital for
Sick Children.
H S Joffe
S C Jordan
Correspondence to
Mr J D Wisheart,
Department of Cardiac
Surgery,
Bristol Royal Infirmary,
Bristol BS2 8HW.
Accepted for publication
11 November 1992.


The other patient had resection of the coarctation segment distal to the left subclavian artery with end to end anastomosis at the age of four months.

The Senning procedure was performed during profoundly hypothermic circulatory arrest and myocardial protection was acheived with cold crystalloid cardioplegia. The patients were reperfused and rewarmed with a cannula inserted into the left atrial appendage. Special care was taken to ensure that all the systemic venous pathways were adequate in size. The inferior vena caval pathway was always capacious. To avoid obstruction of the superior vena caval pathway, it was necessary both to ensure that sufficient right atrial wall was used in its construction, and that it was not narrowed by the suture line that passes outside the superior vena cava as part of the newly created pulmonary venous pathway. The pulmonary venous pathway was never enlarged with a patch but the right superior pulmonary vein was incised in all cases to ensure an adequate channel. ${ }^{15}$ A Dacron patch was used in 18 cases to complete the interatrial septum only. No other foreign patch material was used in constructing the venous pathways. Blood from the coronary sinus drained to the right ventricle.

\section{CLINICAL AND HAEMODYNAMIC REVIEW}

Clinical outcome was assessed between October 1988 and March 1989 for all surviving patients except one, who now lives abroad and for whom clinical data has been obtained. The postoperative follow up period was between two and six years with an average of $49 \cdot 3(14 \cdot 1)$ months.

Operative mortality was defined as death within 30 days of surgery and late mortality as death occurring more than one month after surgery. Variables are expressed as mean (SD). Postoperative actuarial survival was calculated with the product limit method of Kaplan and Meier. ${ }^{16}$

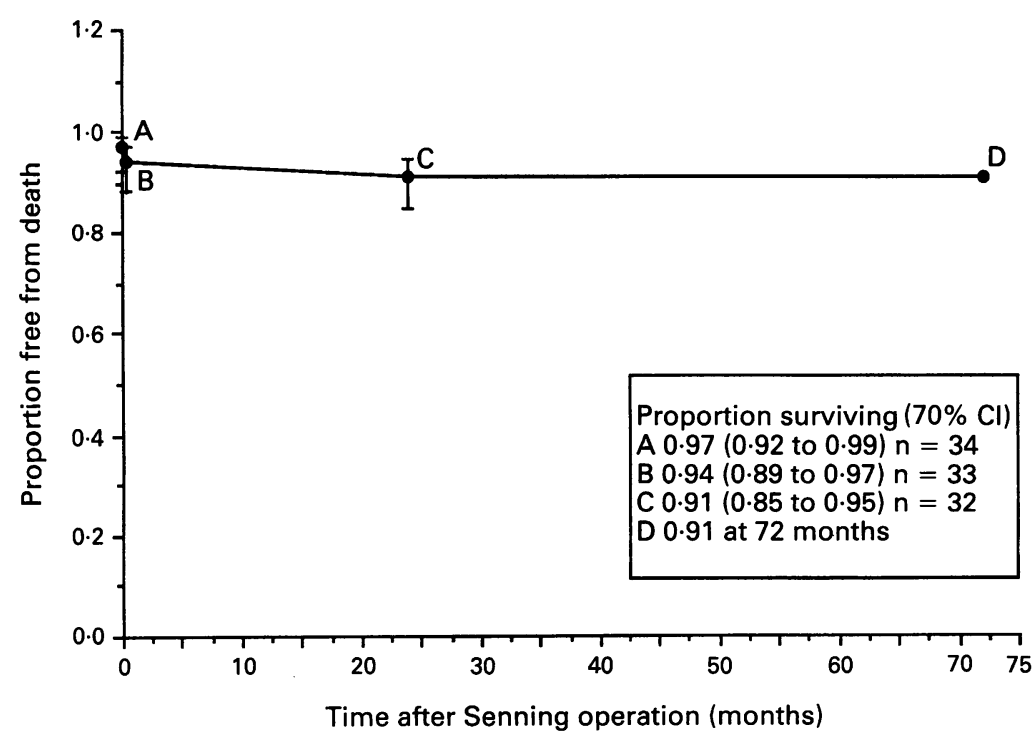

Figure 1 Actuarial survival showing proportion surviving up to 72 months after the Senning operation with $70 \%$ confidence intervals ( $70 \% \mathrm{CIs}$ ).
Elective cardiac catheterisation was performed one to two years after operation in 29 patients (age $36(12 \cdot 3)$ months). Cardiac catheterisation was refused by the parents of two patients. Three patients have died. In one patient the catheterisation was performed abroad and only haemodynamic data are available.

The catheterisation procedure was performed under general anaesthesia with standard techniques. Pressures were taken on withdrawing the catheter from the superior vena cava to the systemic venous atrium and to the inferior vena cava in all cases. In 26 patients recordings were also taken simultaneously from the pulmonary artery wedge position and the pulmonary venous atrium entered retrogradely through the aorta, right ventricle, and the tricuspid valve.

Angiograms of the superior vena cava, inferior vena cava and pulmonary venous pathways were performed in anterioposterior and lateral projections. The diameters of the systemic and pulmonary venous pathways were measured at their narrowest points, which were in the region of the cavoatrial junction and where the confluence of the pulmonary veins joined the pulmonary venous atrium. Because of the variation of the diameters during the cardiac cycle in the systemic pathways the maximal and minimal diameter were measured at the defined positions. The actual diameter of the pathway was calculated by comparison with the known diameter of the catheter used for the investigation.

An assessment of the degree of retrograde filling of the azygous vein after injection of dye into the superior vena cava was recorded in 27 patients and graded according to the scale: $I=$ minimal filling of origin of the azygous vein, $\mathrm{II}=$ filling of azygous vein above the diaphragm, III = filling of azygos vein to below the diaphragm.

\section{Results}

CLINICAL

Figure 1 shows actuarial survival. There were two operative deaths $(6 \%)$, one occurring early in the series due to poor cardiac function on the first postoperative day, and the second due to inhalation of gastric contents on the sixth post operative day in a patient progressing well. There was a single sudden late death after two years that was assumed to be due to an arrhythmia although a recent electrocardiogram had shown sinus rhythm. Postmortem examination showed no other abnormality. The 31 surviving patients $(91 \%)$ are all clinically well with no elevation of jugular venous pressure and require no regular cardiac medication. Surface electrocardiographic recordings show that all patients are in sinus rhythm except one who shows the Wenckebach rhythm (routine 24 hour Holter monitoring of the electrocardiogram has not been performed). No patient has required insertion of a pacemaker and reoperation for pathway obstruction has not so far been required. Three patients who had had a 
cerebrovascular accident before the Senning procedure, have made sustained progress since operation but have mild residual neurological deficits.

\section{HAEMODYNAMICS}

At postoperative catheterisation the mean oxygen saturation in the aorta was $96.5 \%$ $(1 \cdot 3 \%)$ and the cardiac index $5 \cdot 2(1 \cdot 2) 1 / \mathrm{m}^{2}$.

A minimal interatrial shunt was seen in three patients on angiography but oxygen saturations did not show any calculable shunt.

Figure 2 (A and B) shows traces from two patients, one with and one without a peak pressure gradient in the systemic venous pathways. In these patients the minimum systemic venous atrial pressure was consistently lower than the minimum superior vena caval pressure. A difference in the mean pressures is therefore present and the mean and peak pressure gradients were recorded in all cases. Figure 3 shows the individual values for the mean pressure gradients in the pathways. The average value of the mean pressure gradients in the superior vena caval pathway was 2.0 $(1.7) \mathrm{mm} \mathrm{Hg}$ with an average peak pressure gradient of $1.2(1.4) \mathrm{mm} \mathrm{Hg}$. A large gradient was present in two patients with mean gradients of $7 \mathrm{~mm} \mathrm{Hg}$. The average mean and peak gradients for the inferior vena caval pathway were $0.7(1.0) \mathrm{mm} \mathrm{Hg}$ and $0.2(0.6)$ $\mathrm{mm} \mathrm{Hg}$. The average gradient between the mean pulmonary wedge and the pulmonary venous atrial pressures was $1 \cdot 4(1 \cdot 1) \mathrm{mm} \mathrm{Hg}$. A gradient of $5 \mathrm{~mm} \mathrm{Hg}$ was present in one
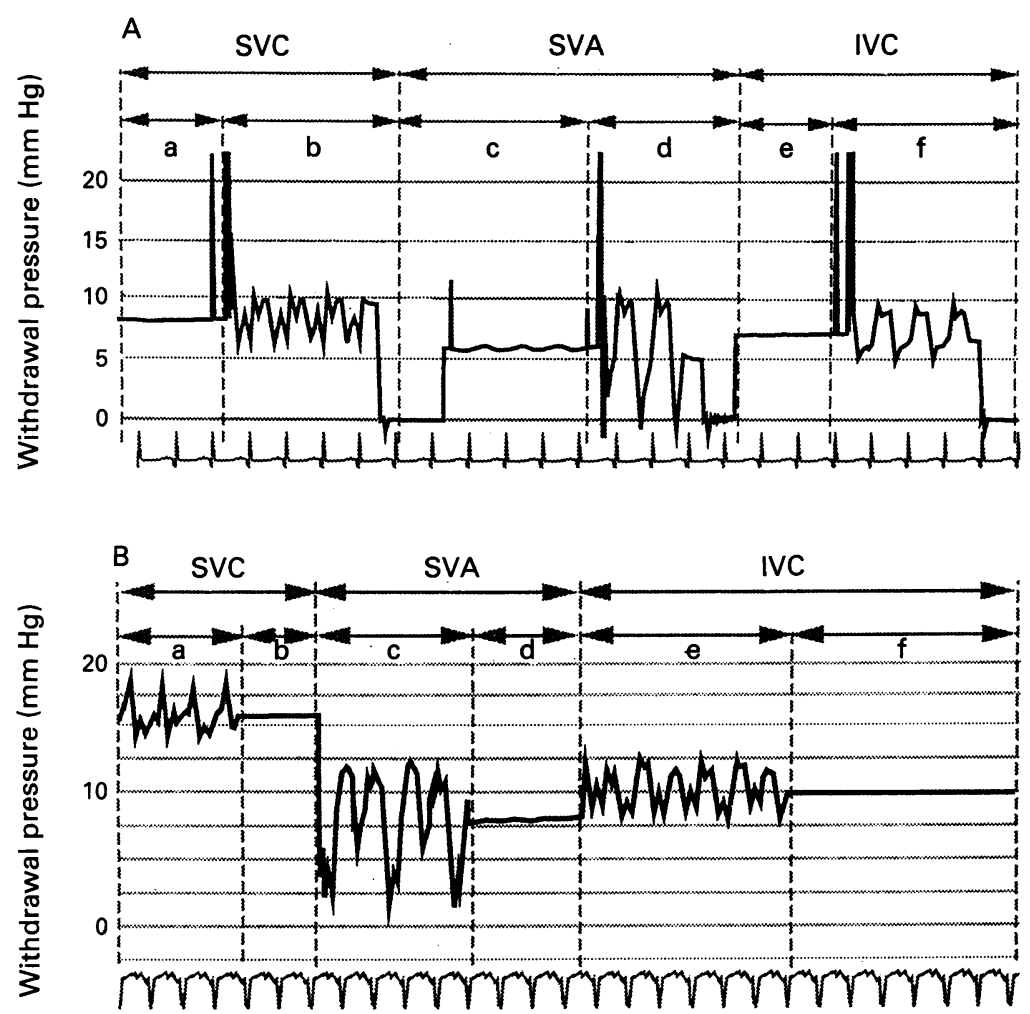

Figure 2 (A) Withdrawal pressure trace from child with no gradient between the peak pressures of superior vena cava (b) and systemic venous atrium (d). There is, however, $a$ gradient of $2 \mathrm{~mm} \mathrm{Hg}$ between the mean SVC pressure (a), and mean SVA pressure (c). Inferior vena cava pressures are also shown. (B) Withdrawal pressure trace from child with a gradient between peak pressures in $S V C$ (a) and $S V A$ (c). The gradient between mean $S V C$ (b) and $S V A$ (d) pressures is $8.2 \mathrm{~mm} \mathrm{Hg}$. (SVC, superior vena cava; SVA, systemic venous atrium; IVC, inferior vena cava).

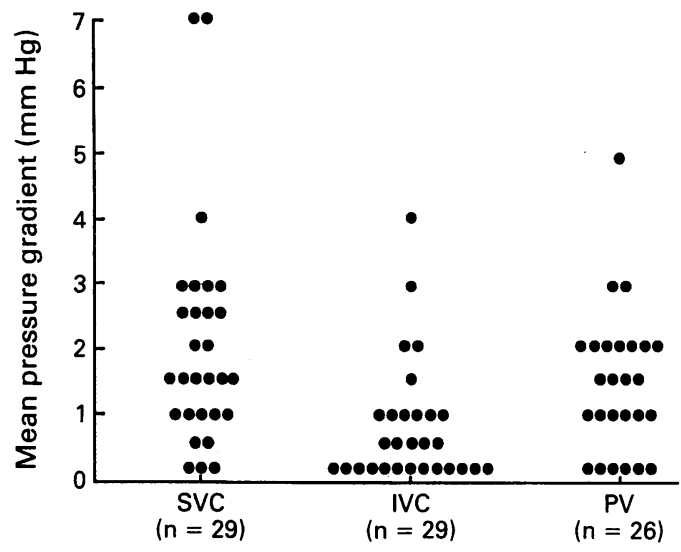

Figure 3 Individual values of mean pressure gradient in SVC, IVC, and pulmonary venous pathways PV (abbreviations as for fig 2).

symptom free patient with normal lung fields on radiography of the chest.

\section{ANGIOGRAPHY}

The mean maximum and minimum diameters of the narrowest part of the systemic venous pathways were $11 \cdot 1(2 \cdot 8) \mathrm{mm}$ and $7 \cdot 5$ $(1 \cdot 7) \mathrm{mm}$ for the superior vena caval pathway; and $15.0(2.8) \mathrm{mm}$ and $11.3(2.3) \mathrm{mm}$ for the inferior vena caval pathway (fig 4). Of the two patients with significant gradients the superior vena caval pathway diameter was fixed at $4.8 \mathrm{~mm}$ in one, and was $7.5 \mathrm{~mm}$ (maximum diameter) and $6.5 \mathrm{~mm}$ (minimum) in the other (fig 5A). The mean diameter for the pulmonary venous pathway was $19.5(3.2) \mathrm{mm}$.

In 17 patients there was no retrograde flow in the azygous vein (fig 4). Minimal flow (grade I) was found in six patients, moderate flow (grade II) in two patients, and flow to below the diaphragm (grade III) in two (fig 5B). The two patients in grade III also had the highest gradients in the superior vena caval pathway $(7 \mathrm{~mm} \mathrm{Hg})$. On clinical examination, however, the jugular venous pressure

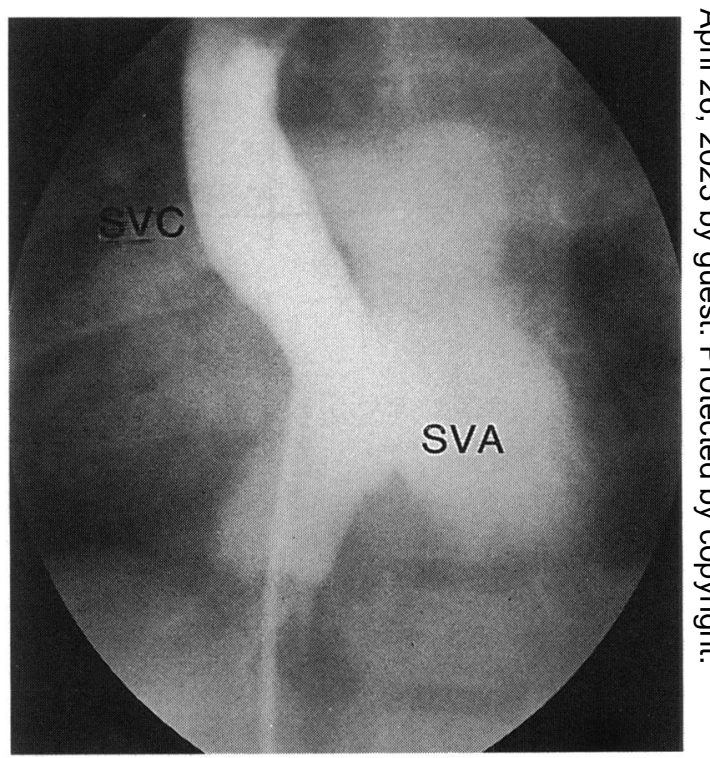

Figure 4 Angiogram after Senning operation showing systemic venous pathway with no venous obstruction and with no azygos filling. (abbreviations as for fig 2). 
Figure 5 (A) Angiogram after Senning operation showing obstruction at the junction of SVC and SVA (two arrows), with early filling of the azygos vein (AV). (abbreviations as for fig 2). (B) The same patient showing later filling patient showing later filling
of azygos vein to below the diaphragm-grade III (abbreviations as for fig 2).
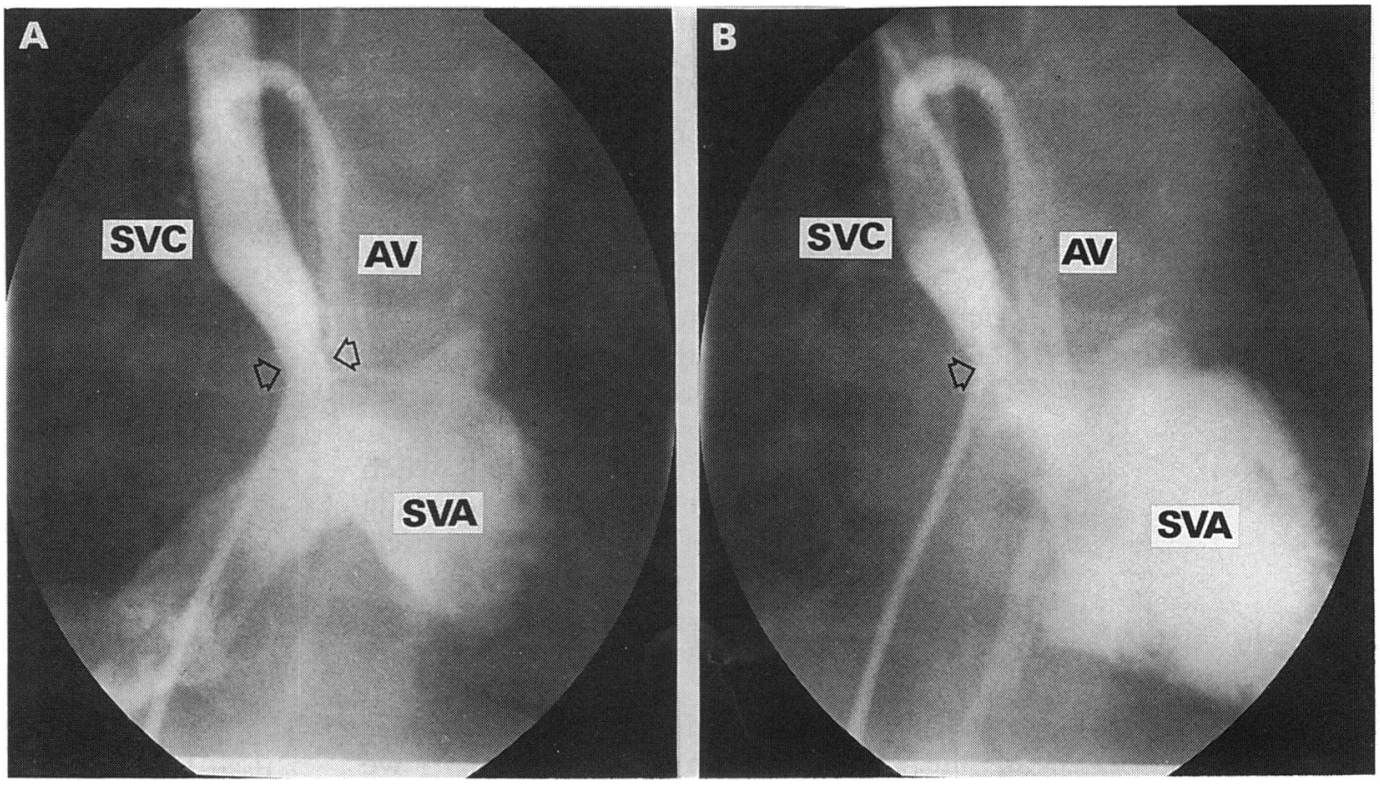

was not elevated in either case. One of these patients was symptom free and the second became cyanosed only during upper respiratory tract infections. Neither patient requires regular medication.

\section{Discussion}

Encouraging results with the Senning procedure for the physiological correction of transposition of the great arteries have been reported from a number of centres. ${ }^{17-19}$ Turina et al reported a 20 year experience of the operation that included 121 patients with simple transposition who survived surgery. ${ }^{20}$ Actuarial survival at five and 10 years was $95 \%$ and $92 \%$, with improved late survival in those operated on since 1977. The principle causes of late death were dysrhythmia (eight patients) and heart failure (six patients). There were no symptoms in $83 \%$ of patients at 10 years. In our study of 34 patients with simple transposition survival after the Senning repair is of the same order, although the duration of follow up is shorter.

Although a relatively high incidence of reoperation after the Mustard procedure is well recognised, ${ }^{21-23}$, it remained below $5 \%$ in some centres. ${ }^{23-24}$ Comparative studies show a lower incidence of reoperation after the Senning procedure ${ }^{172526}$ and in 1980 Bender et al showed that the SVC pressure gradient was significantly lower in patients after the Senning than after the Mustard operation. ${ }^{21}$ Reoperation rates of $18 \%$ have been reported for obstruction of the venous pathways after the Mustard procedure and 3\% after the Senning repair. ${ }^{2023}$ In our early experience there was a high rate of reoperation after the Mustard procedure mainly for pulmonary venous pathway obstruction. ${ }^{4}$ We have used the Senning procedure since 1983 and there has been no need for reoperation in this series of 34 patients. A Dacron patch was used to complete the interatrial septum in $53 \%$ but the pulmonary venous atrium was never enlarged with a patch. The right upper pulmonary vein, however, was incised in all patients to increase the diameter of the pulmonary venous pathway. We believe that the avoidance of the use of foreign material to enlarge the atria other than the small patch for closure of the atrial septal defect reduces the need for reoperation after the modified Senning operation as compared with the Mustard operation, where foreign material is extensively used in construction of the venous pathways.

In this study we have evaluated in detail the haemodynamic and angiographic features in 29 patients recatheterised one to two years after Senning repair. Analysis of the pressure waveform has shown that the minimum pressure in the superior vena cava is higher than the minimum pressure in the systemic venous atrium even in the absence of a difference in the peak pressures. This has led to a greater difference in the mean pressure gradients than in the peak pressure gradients and both values are therefore reported. This also occurs after the Mustard operation ${ }^{4} 6$ and may be due to the relatively small size of the atria and reduced compliance of the venous pathways. Despite this, all but two patients had a negligible mean gradient in the systemic venous pathway. A mean gradient of $7 \mathrm{~mm}$ $\mathrm{Hg}$ was present between the superior vena cava and systemic venous atrium in two patients who were clinically well and without evidence of a raised jugular venous pressure. Retrograde azygos vein flow to below the diaphragm was only seen in these two patients who also showed angiographic evidence of a narrow junction between the superior vena cava and the systemic venous atrium. It is not clear whether the retrograde azygous flow in these patients will protect them from the consequences of restricted flow into the systemic venous atrium or whether they will need reoperation in the future. A gradient of $5 \mathrm{~mm} \mathrm{Hg}$ in the pulmonary venous pathway was present in only one symptom free patient with a normal chest radiograph; reoperation has not been recommended. 
Sutures in the region of the sinoatrial node should always be placed carefully ${ }^{2}$ to $\mathrm{min}$ imise occurrence of rhythm disturbances that are associated with both the Senning and Mustard operations, ${ }^{27}$ and we have meticulously done this. In the patients reported here only abnormalities of $\mathrm{P}$ wave morphology have been seen on a 12 lead electrocardiogram, but we have not performed routine 24 hour monitoring of the electrocardiogram. There has been one presumed sudden death in this group of patients.

Promising results after the arterial switch procedure have now been reported indicating that normal function of the systemic ventricle can be expected and dysrhythmias do not seem to be a problem. ${ }^{28} 29$ Operative survival of $96 \%$ can be achieved, with more favourable results in neonates than when operation is performed later in the first year of life. ${ }^{13}$ In common with others, ${ }^{19}{ }^{32}$ we believe that there is still a place for correction of simple transposition of the great arteries by atrial redirection especially after a few weeks of life. Impaired right ventricular function after both the Senning and the Mustard procedures may have been due to poor perioperative myocardial preservation before the use of cardioplegia. ${ }^{18}$ The report of Turina et al with a follow up of 20 years emphasises that in simple transposition of the great arteries the incidence of systemic ventricular failure is much lower than in complex transposition of the great arteries and that there is no evidence of increasing frequency of systemic ventricular failure, with increasing duration of follow up. ${ }^{20} \mathrm{He}$ reports that the morphological right ventricle can adequately support the systemic circulation for up to 20 years after the Senning procedure in over $90 \%$ of patients.

The recent report of the North American Congenital Heart Surgeons draws attention to the fact that neonatal anatomical correction avoids the morbidity that may occur during infancy while awaiting the atrial operation..$^{13}$ The occurrence of a cerebrovascular accident before surgery in three patients in this series underlines this point, and is an important reason for undertaking the Senning operation at an earlier age than the 18 months reported in this study; in our own practice the operation is now performed routinely between six and 12 months of age, and we have not noticed that there is an increase in technical difficulties in the younger patients.

We have shown by detailed haemodynamic studies after the Senning operation that with careful operative technique adequate venous pathways can be created and reoperation avoided in over $93 \%$ of patients. Azygos vein run off may account for the absence of clinical features in the two patients with moderately severe stenosis in the superior vena caval pathway. Careful cardiological follow up with non-invasive monitoring of the venous pathways is essential to ensure that patients with obstruction of a pathway are identified. ${ }^{22} 3031$
We thank Dr Mark Jackson of the Department of Anatomy, Alderhay Children's Hospital, Liverpool for help in the computation of actuarial survival and Miss $S$ Harris for typing the manuscript.

1 Senning A. Surgical correction of transposition of the great vessels. Surgery 1959,45:966-80.

2 Quaegebeur JM, Rohmer J, Brom AG. Revival of the Senning operation in the treatment of transposition of the great arteries. Preliminary report on recent experithe great arteries. Preliminary

3 Hagler DJ, Ritter DG, Mair DD, Davis GD, McGoon DC. Clinical, angiographic, and haemodynamic assessment of the late results after Mustard's operation. Circulation 1978;57:1214-20

4 Joffe HS, Wisheart JD, Jordan SC. The late haemodynamic evaluation of the Mustard operation for transposition of the great arteries [abstr]. $\mathrm{Br}$ Heart $f$ 1983;49:293.

5 Ebert PA, Gay WA, Engle MA. Correction of transposition of the great arteries. Relationship of the coronary sinus and post operative arrhythmias. Ann Surg 1974;180:433-8.

6 Clarkson PM, Barratt-Boyce BG, Neutze JM. Late dysrhythmias and disturbances of conduction following Mustard operation for complete transposition of the Mustard operation for complete transp. Circulation 1976;53:519-24.

7 Haller JA, Crisler C, Brawley R, Cameron J. Mustard operation for transposition of the great vessels. $f$ Thorac Cardiovasc Surg 1969;58:296-300.

8 Mustard WT, Keith JD, Trusler GA, Fowler R, Kidd L. The surgical management of transposition of the great vessels. F Thorac Cardiovasc Surg 1964;48:953-8.

9 Warnes CA, Somerville J. Transposition of the great arteries: late results in adolescents and adults after the Mustard procedure. Br Heart $\mathcal{f} 1987 ; 58: 149-55$.

10 Jatene AD, Fontes VF, Paulista PP, Souza LCB, Neger F, Galantier M, Souza JE. Successful anatomic correction of transposition of the great vessels. A preliminary report. Arg Braz Cardiol 1975;228:461.

11 Jatene AD, Fontes VF, Souza LCB, Paulista PP, Neto CA, Souza JEMR. Anatomic correction of the great arteries. $\mathcal{F}$ Thorac Cardiovasc Surg 1982;83:20-6.

12 Yacoub MH, Bernhard A, Radley-Smith R, Lange P, Sievers H, Heintzen P. Supravalvar pulmonary stenosis after anatomic correction of transposition of the great arteries. Circulation 1982;66(suppl 1):192-7.

13 Norwood WI, Dobell AR, Freed MD, Kirklin JW, Blackstone $\mathrm{EH}$, and the Congenital Heart Surgeons Society. $\mathcal{F}$ Thorac Cardiovasc Surg 1988;96:854-63.

14 Rashkind WJ, Miller WW. Transposition of the great arteies. The results of palliation by balloon septostomy in thirty one infants. Circulation 1968;38:453.

15 Pacifico A. Concordant transposition-Senning operation. In: Stark J, de Leval M, eds. Surgery for congenital heart defects. London: Grune and Stratton, 1983:345.

16 Kaplan EL, Meier P. Non-parametric estimation from incomplete observations. $\mathcal{f} A m$ Stat Ass 1958;53: 457-81.

17 Deleon VH, Hougen TJ, Norwood WI, Lang P, Marx GR, Casteneda A. Results following the Senning procedure for transposition of the great arteries with intact ventricular septum. Circulation 1984;70:121-5.

18 Graham TP, Burger J, Bender HW, Hammon JW, Boucek RJ Jr, Appleton S. Improved right ventricular function after intra-atrial repair of transposition of the great arteries. Circulation 1985;72(suppl ii):45-51.

19 George BL, Laks H, Klitzner TS, Friedman WF, Williams RG. Results of the Senning procedure in infants with simple and complex transposition of the great arteries. Am f Cardiology 1987;59:426-30.

20 Turina M, Siebenmann R, Nussbaumer P, Senning A. Long-term outlook after atrial correction of transposition of great arteries. $\mathcal{f}$ Thorac Cardiovasc Surg 1988;95:828-35.

21 Bender HW, Graham TP Jr, Boucek RJ Jr, Walker WE, Boerth RG. Comparative operative results of the Senning and Mustard procedures for transposition of the great arteries. Circulation 1980;62(suppl i): of the gr

22 Smallhorn JF, Gow R, Freedom RM, Trusler GA, Olley P, Pacquet M, et al. Pulsed Doppler echocardiographic assessment of the pulmonary venous pathway after the Mustard or Senning procedure for transposition of the great arteries. Circulation 1986;73:765-74.

23 Williams WG, Trusler GA, Kirklin JW, Blackstone EH, Coles JG, Izukawa T, Freedom RM. Early and late results of a protocol for simple transposition leading to an atrial switch (Mustard) repair. $\mathcal{F}$ Thorac Cardiovas Surg 1988;95:717-26.

24 Ashraf M, Cotroneo J, DiMarco D, Subramanian S. Fate of long-term survivors of Mustard procedure (Inflow Repair) for simple and complex transposition of the Repair) for sin Thorac Surg 1986;42:385-9.

25 Gram TP. Haemodynamic residua and sequelae following intratrial repair of transposition of the great ing intra-atrial repair of transposition of the great arteries. A review. Paediatr Cardiol 1982;2:203-13.

26 Park SC, Neches WH, Mathews RA, et al. Haemodynamic function after the Mustard procedure for transposition of the great arteries. Am Cardio 
27 Hayes C, Gersony WM. Arrhythmias after the Mustard operation for transposition of the great arteries; A long operation for transposition of the great arte

28 Casteneda AR, Norwood WI, Jones RA, Colon SD, Saunders SP, Lang P. Transposition of the great arteries and intact ventricular septum; anatomic repair in the neonate. Ann Thorac Surg 1984;38:438-43.

29 Okuda H, Nakazawa M, Imai Y, Kurusawa H, Takanashi Y, Hoshino S, Takao A. Comparison of ventricular function after Senning and Jatene procedures for complete transposition of the great arteries. Am $\mathcal{F}$ Cardiol 1985;55:530-4.

30 Chin AJ, Saunders SP, Williams RG, Lang P, Norwood
WI, Casteneda AR. Two dimensional echocardiographic assessment of caval and pulmonary venous pathways after the Senning operation. Am $f$ Cardiol 1983;52: 118-26. Senning operation. Am $\mathcal{F}$ Cardiol 1983;52:

31 Satomi G, Nakamura K, Takao A, Imai Y. Two dimensional echocardiographic detection of pulmonary venous channel stenosis after Senning's operation. Circulation 1983;68:545-9.

32 Darvell FJ, Rossi IR, Rossi M, Fayers P, Anderson RH Rigby ML, et al. Intermediate to late results of Mustard's procedure for complete transposition of the great arteries with an intact ventricular septum. Br Heart f 1988;59:468-73. 